\title{
Interface Engineering of Metal Oxides using Ammonium Anthracene in Inverted Organic Solar Cells
}

\author{
Il Jeon, ${ }^{\dagger}$ Sasa Zeljkovic, ${ }^{\S}$ Kei Kondo, ${ }^{*}$ Michito Yoshizawa, ${ }^{\ddagger}$ and Yutaka Matsuo ${ }^{\dagger, \# *}$ \\ †: Department of Mechanical Engineering, School of Engineering, The University of Tokyo, 7-3-1 \\ Hongo, Bunkyo-ku, Tokyo 113-8656, Japan \\ $\S$ : Department of Chemistry, Faculty of Sciences, University of Banja Luka, Mladena Stojanovica 2, \\ 78000 Banja Luka, Bosnia and Herzegovina \\ \#: Laboratory for Chemistry and Life Science, Institute of Innovative Research, Tokyo Institute of \\ Technology, 4259 Nagatsuta, Midori-ku, Yokohama 226-8503, Japan \\ \#: Hefei National Laboratory for Physical Sciences at the Microscale, University of Science and \\ Technology of China, Hefei, Anhui 230026, China
}

Corresponding author: Y. Matsuo matsuo@photon.t.u-tokyo.ac.jp

\section{Contents:}

\section{Experimental}

2. PCE Evaluations

3. Energetics Analyses

4. Other Properties of AA

5. Fullerene Catching Ability

6. Device Stability 


\section{Experimental}

Device Fabrication. For the reference device, ITO substrates with size $15 \times$ $15 \mathrm{~mm}^{2}$ and an active area of $3 \times 3 \mathrm{~mm}^{2}$ with a sheet resistance of $6 \Omega /$ square (Kuramoto Co., Ltd.) were sonicated in cleaning surfactant (Semi Clean, M-Lo), water, acetone and 2-isopropanol for $15 \mathrm{~min}$ each. The substrates were then dried with $\mathrm{N}_{2}$ gun. ITO substrates were exposed to $\mathrm{UV} / \mathrm{O}_{3}$ for $30 \mathrm{~min}$ in order to remove any remaining organic impurities. Water solutions with anthracene concentration ranging from $2.5 \mathrm{mg} \mathrm{mL}^{-1}$ to $9 \mathrm{mg} \mathrm{mL}^{-1}$ were dropped on the active surface at $25{ }^{\circ} \mathrm{C}$ for 20 min. The water solution was covering only active area without interfering with the contacts. After 20 minutes residual solution was blown with $\mathrm{N}_{2}$ and (in the case of $\mathrm{ZnO}$ treatment) rinsed with water, and then dried with $\mathrm{N}_{2}$ gun. In the case of ITO experiment was done without rinsing.

$\mathrm{ZnO}$ sol-gel films were prepared using the method reported by Heeger et al. ${ }^{1}$ The metal oxides were baked at $200{ }^{\circ} \mathrm{C}$ before depositing the photoactive layer.

For the photoactive layer deposition, PTB7 and [6,6]-phenyl C71-butyric acid methyl ester $\left(\mathrm{PC}_{71} \mathrm{BM}\right)$ were purchased from Luminescence Technology Corporation and used as received without further purification. A blend solution of PTB7 and $\mathrm{PC}_{71} \mathrm{BM}$ was prepared in a mixed solvent of chlorobenzene $(99 \%, \mathrm{CB})$ and $1,8-$ diiodoctane (DIO) at a 97:3 ratio. PTB7 $(10 \mathrm{mg})$ and $\mathrm{PC}_{71} \mathrm{BM}(15 \mathrm{mg})$ were initially dissolved in $\mathrm{CB}$ inside a nitrogen glove box $(0.97 \mathrm{~mL})$. The solution was left stirring overnight at $60{ }^{\circ} \mathrm{C}$. After $24 \mathrm{~h}$, the corresponding amount of DIO $(30 \mu \mathrm{L})$ was added. The new solution was stirred $1 \mathrm{~h}$ at $70{ }^{\circ} \mathrm{C}$. The solution of PTB7:PC 71 BM:DIO (80 $\mathrm{nm}$ ) was spin-coated at $1500 \mathrm{rpm}$ for $60 \mathrm{~s}$ on $\mathrm{ZnO}$ layer to give approximately 100 $\mathrm{nm}$. For the cathodes, $\mathrm{Ag}(100 \mathrm{~nm})$ was deposited by vacuum thermal evaporation at the rate of $0.2 \AA / \mathrm{s}$.

Characterizations. Current-voltage $(J-V)$ characteristics were measured by software-controlled source meter (Keithley 2400) in dark conditions and 1 sun AM $1.5 \mathrm{G}$ simulated sunlight irradiation $\left(100 \mathrm{~mW} / \mathrm{cm}^{2}\right)$ using a solar simulator (EMS35AAA, Ushio Spax Inc.), which was calibrated using a silicon diode (BS-520BK, Bunkokeiki). Topography images were recorded using an AFM operating in tapping mode (SPI3800N, SII). Shimadzu UV-3150 was used for the UV-vis-NIR 
measurement. X-ray Diffraction (XRD; Rigaku Smartlab diffractometer) using $\mathrm{Cu} \mathrm{K} \alpha$ radiation operating with a power of $9 \mathrm{~kW}(45 \mathrm{kV}, 200 \mathrm{~mA})$ was used. Core level photoemission measurements were performed by XPS (PerkinElmer, 5400MC) using monochromatic Al Ka radiation. The XPS resolution was estimated to be $\approx 1 \mathrm{eV}$ and the energy offset was calibrated using the surface $C$ 1s peak. Valence band information and Fermi levels were measured by Riken Keiki PYS-A AC-2 and kelvin probe S spectroscopy in air (ESA), respectively. They were calibrated by Au before the measurement.

The structure of the electron-only device was $\mathrm{Al} / \mathrm{ZnO}$-(surface treatment)/Al. The mobility was determined by fitting the dark current to a model of a single-carrier space charge limited current, which is described by the equation: $J=\frac{9}{8} \varepsilon_{0} \varepsilon_{r} \mu \frac{V^{2}}{L^{3}}$, where $J$ is the current density, $\mu$ is the mobility, $e_{0}$ is the permittivity of free space, $e_{\mathrm{r}}$ is the relative permittivity of the material, $L$ is the thickness of the active layer, and $V$ is the effective voltage. The experimental dark current density $J$ of both P3HT:PCBM and P3HT:mix-PCBM was measured under an applied voltage swept from 0 to -5 $\mathrm{V}^{2,3}$ 


\section{PCE Evaluations}

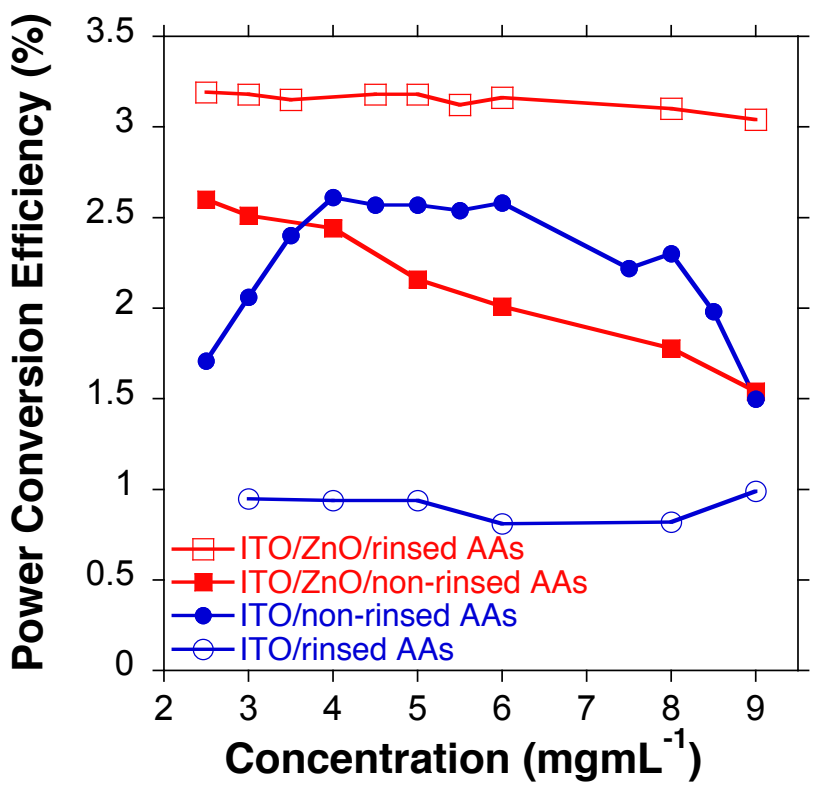

Figure S1. PCE plots of ITO/ZnO/rinsed AAs-based device (red open squares), ITO/non-rinsed AAsbased device (red closed squares), ITO/ZnO/non-rinsed AAs-based device (blue closed circles), and ITO/rinsed AAs-based device (blue open circles), according to AA concentrations.

Table S1. Photovoltaic parameters of ANTHs-applied devices and a reference device under one sun (AM1.5G illumination, $100 \mathrm{~mW} \mathrm{~cm}^{-2}$ ).

\begin{tabular}{|c|c|c|c|c|c|c|c|}
\hline Device & System & $V_{\mathrm{oc}}(\mathrm{V})$ & $\begin{array}{c}J_{\mathrm{SC}} \\
\left(\mathrm{mA} \mathrm{cm}^{-2}\right)\end{array}$ & FF & $\underset{\left(\Omega \mathrm{cm}^{2}\right)}{R_{\mathrm{S}}}$ & $\underset{\left(\Omega \mathrm{cm}^{2}\right)}{R_{\mathrm{SH}^{2}}}$ & PCE (\%) \\
\hline ITO/ZnO/rinsed AAs & \multirow{4}{*}{ P3HT } & $0.60 \pm 0.00$ & $8.89 \pm 0.27$ & $0.58 \pm 0.03$ & 3.5 & $4.8 \times 10^{4}$ & $3.08 \pm 0.12$ \\
\hline ITO/ZnO/non-rinsed AAs & & 0.60 & 8.05 & 0.52 & 5.1 & $3.3 \times 10^{3}$ & 2.54 \\
\hline ITO/rinsed AAs & & 0.32 & 7.90 & 0.39 & 8.7 & $3.8 \times 10^{2}$ & 0.95 \\
\hline ITO/non-rinsed AAs & & $0.59 \pm 0.01$ & $8.23 \pm 0.18$ & $0.53 \pm 0.16$ & 8.3 & $4.1 \times 10^{3}$ & $2.58 \pm 0.02$ \\
\hline ITO/ZnO/rinsed AAs & \multirow{2}{*}{ PTB7 } & $0.76 \pm 0.01$ & $15.1 \pm 0.20$ & $0.70 \pm 0.03$ & 30 & $2.6 \times 10^{6}$ & $8.1 \pm 0.21$ \\
\hline ITO/non-rinsed AAs & & $0.60 \pm 0.00$ & $15.2 \pm 0.18$ & $0.63 \pm 0.01$ & 25 & $2.0 \times 10^{6}$ & $5.8 \pm 0.11$ \\
\hline \multirow{2}{*}{ [Reference] ITO } & P3HT & 0.12 & 0.04 & 0.12 & - & - & 0.05 \\
\hline & PTB7 & 0.28 & 2.9 & 0.21 & - & - & 0.33 \\
\hline \multirow{2}{*}{ [Reference] ITO/ZnO } & Р3HT & $0.60 \pm 0.01$ & $9.20 \pm 0.20$ & $0.52 \pm 0.03$ & 5.2 & $2.8 \times 10^{3}$ & $2.91 \pm 0.21$ \\
\hline & PTB7 & $0.73 \pm 0.03$ & $16.0 \pm 0.46$ & $0.65 \pm 0.12$ & 16 & $6.4 \times 10^{4}$ & $7.5 \pm 0.15$ \\
\hline
\end{tabular}



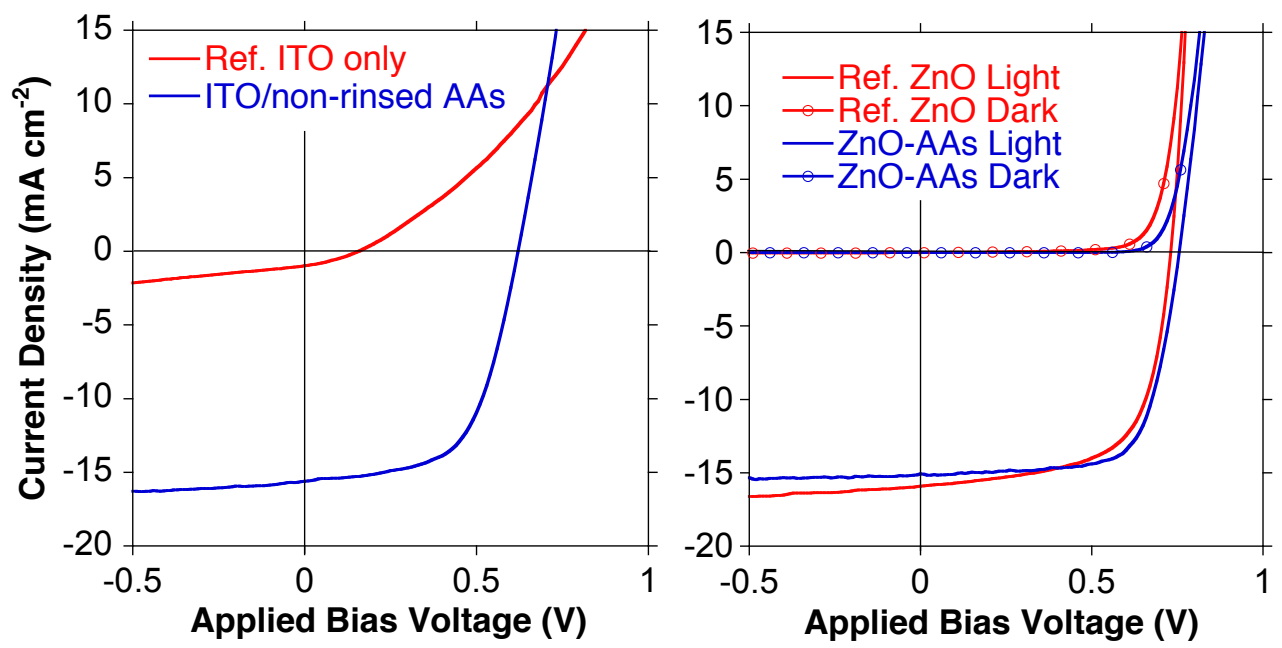

Figure S2. $J-V$ curves of the ITO only devices and the ITO/rinsed AAs-based devices (left); and the $\mathrm{ZnO}$ reference devices and the $\mathrm{ZnO} /$ rinsed AAs devices (right) comprising the PTB7 system. 


\section{Energetics Analyses}

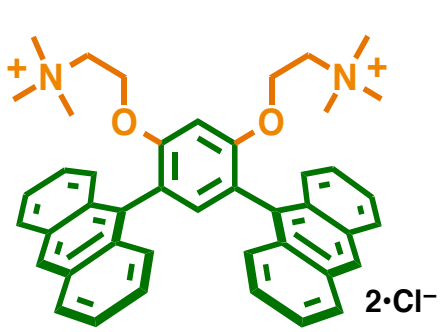

$E_{g}=2.69 \mathrm{eV}$

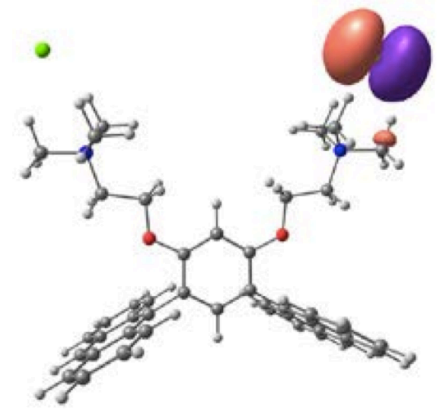

LUMO $=2.25 \mathrm{eV}$

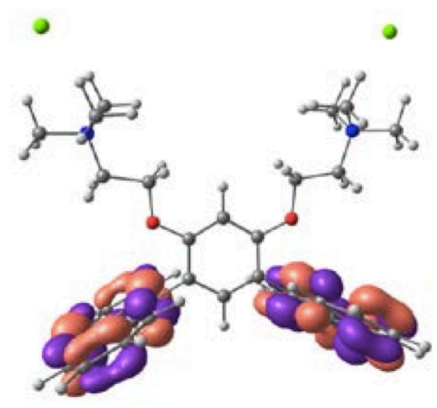

$\mathrm{HOMO}=4.94 \mathrm{eV}$

Figure S3. Chemical structure of the AA surface modifier with a calculated band gap (left), and Gaussian-calculated absolute energy levels of LUMO (middle) and HOMO (right).
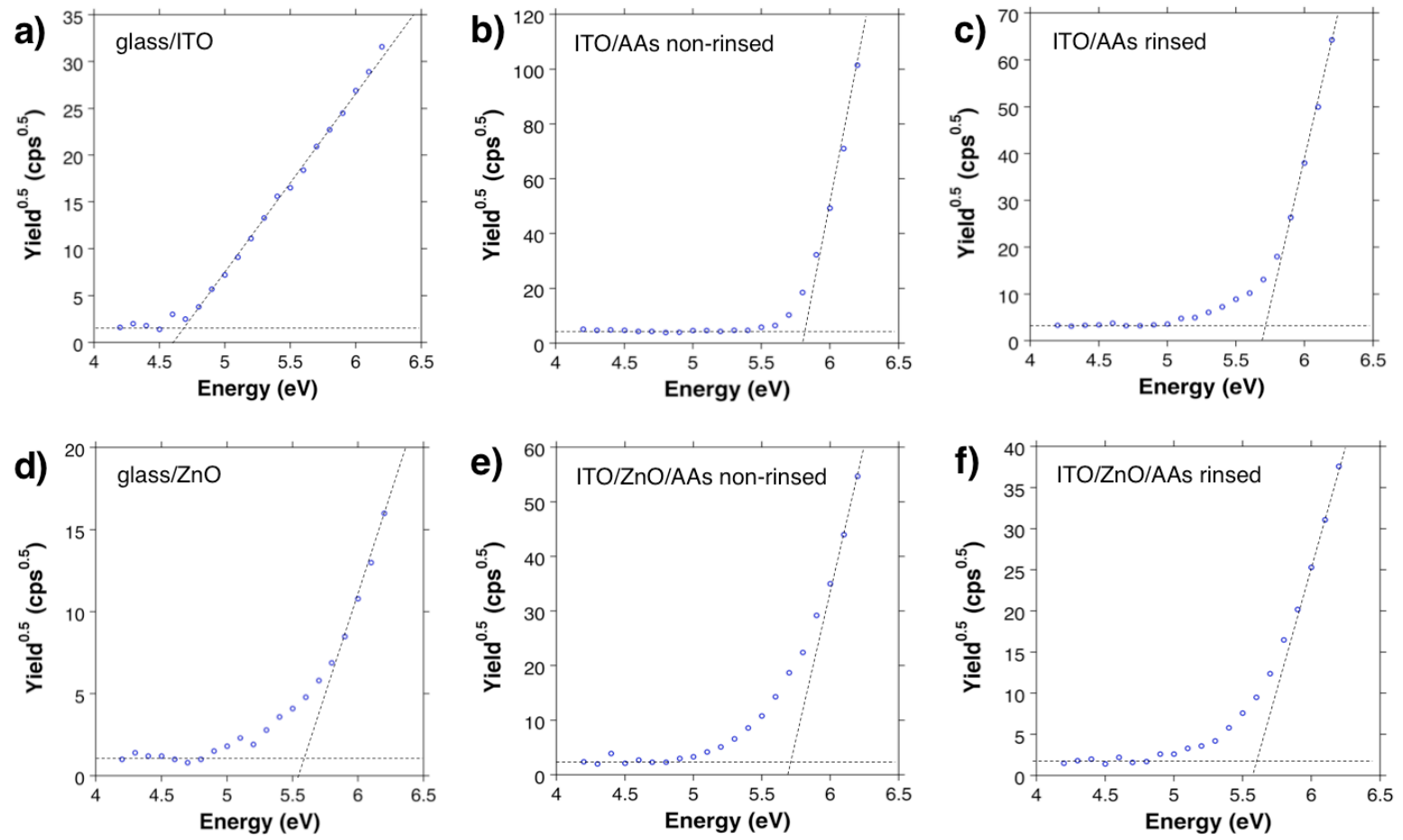

Figure S4. PYS data of a) ITO, b) water-rinsed and c) non-rinsed AA-treated ITO; d) ZnO, e) waterrinsed and f) non-rinsed AA-treated $\mathrm{ZnO}$. 


\section{Other Properties of AA}

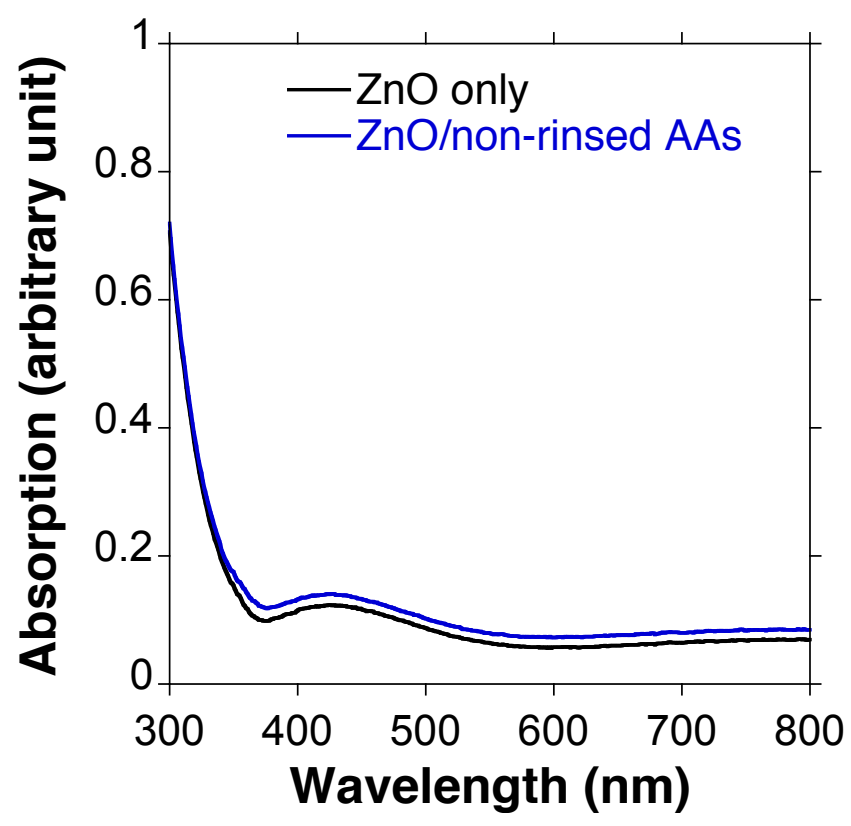

Figure S5. UV-vis spectra of a $\mathrm{ZnO}$ film and an AA-treated $\mathrm{ZnO}$ film

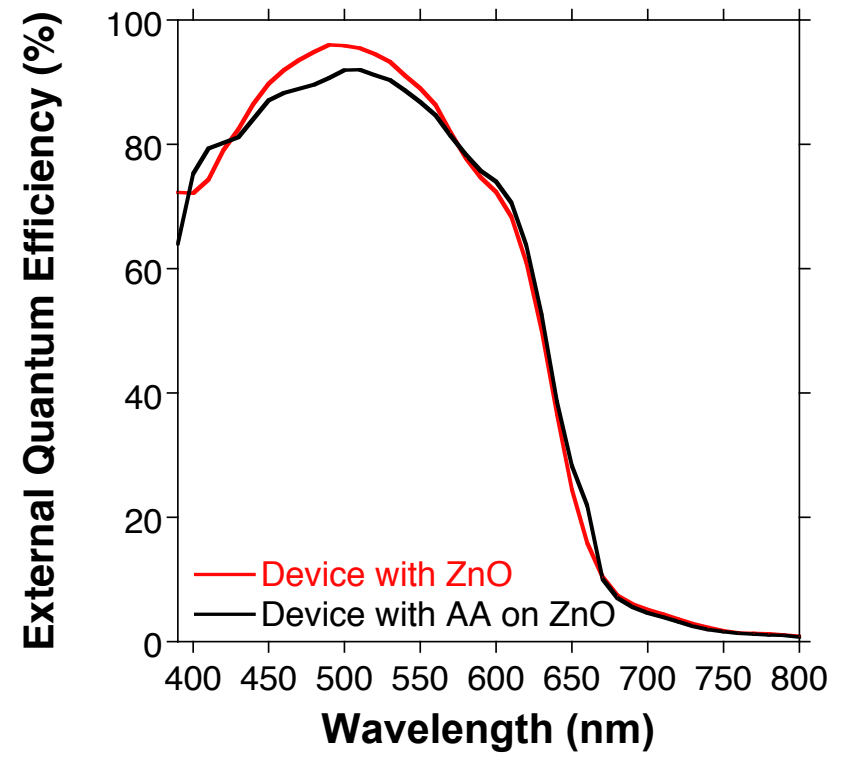

Figure S6. EQE spectra of P3HT:PCBM-based OSCs using ZnO (red) and AA on ZnO (black) 


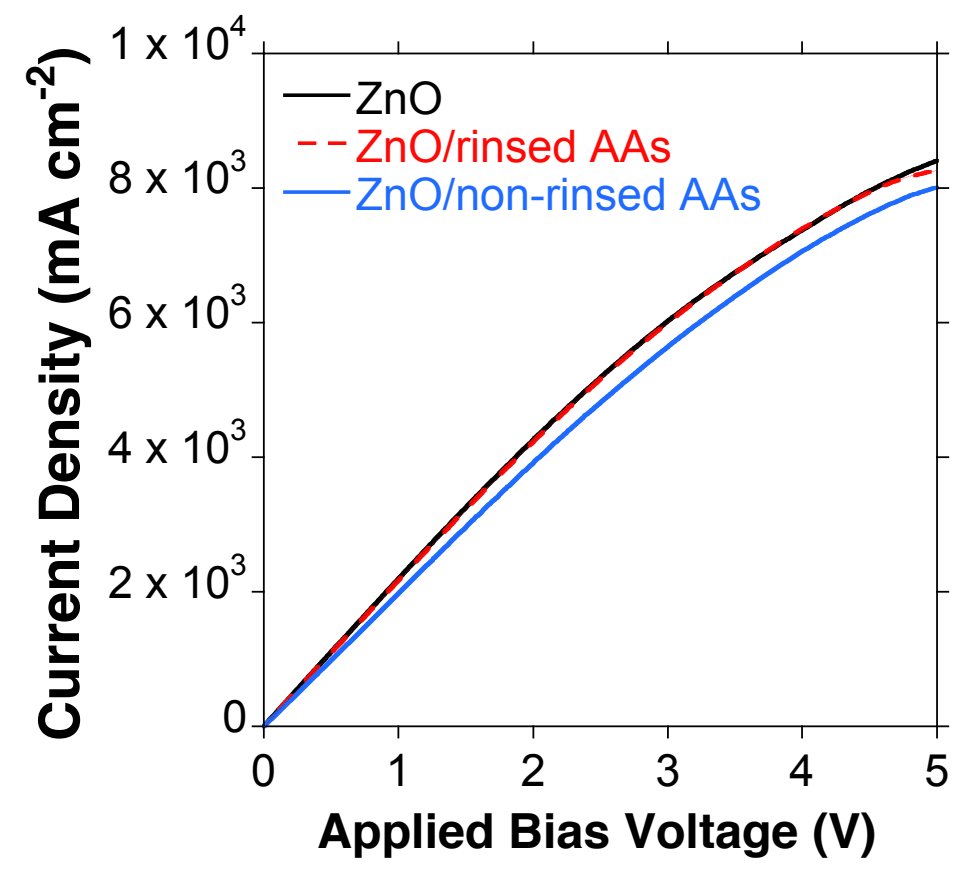

Figure S7. $J-V$ curves of the electron-only devices for SCLC measurement and electron mobilities $(\mu)$ given as an inset with the unit $\left(\mathrm{cm}^{2} \mathrm{~V}^{-1} \mathrm{~s}^{-1}\right)$.

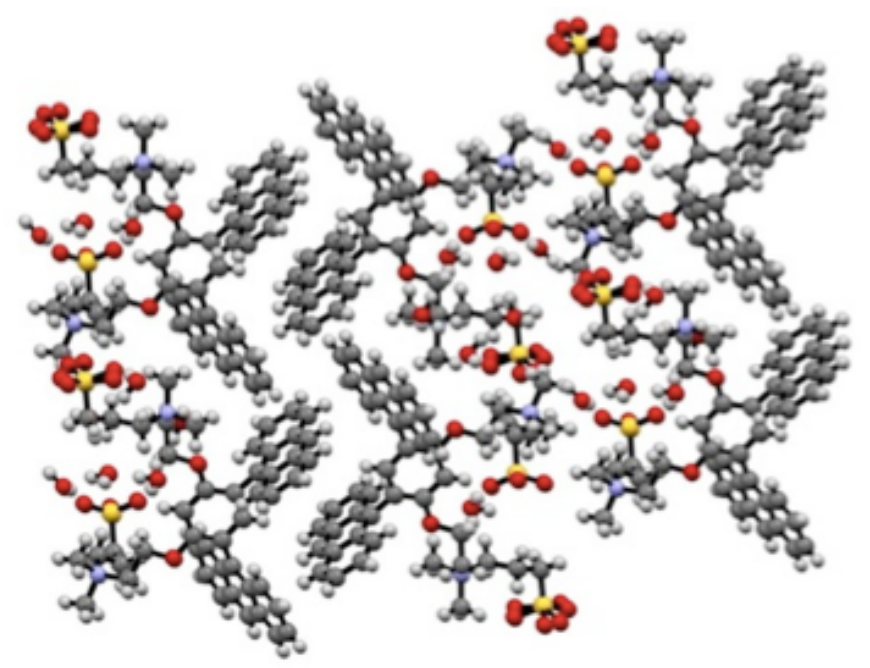

Figure S8. Crystallography of anthracene derivatives where charged ends are to the left and bent polyaromatic groups are facing to the right. The crystal was grown slowly by evaporating a water solution at room temperature for 3 days (CCDC 889326). ${ }^{4}$ 

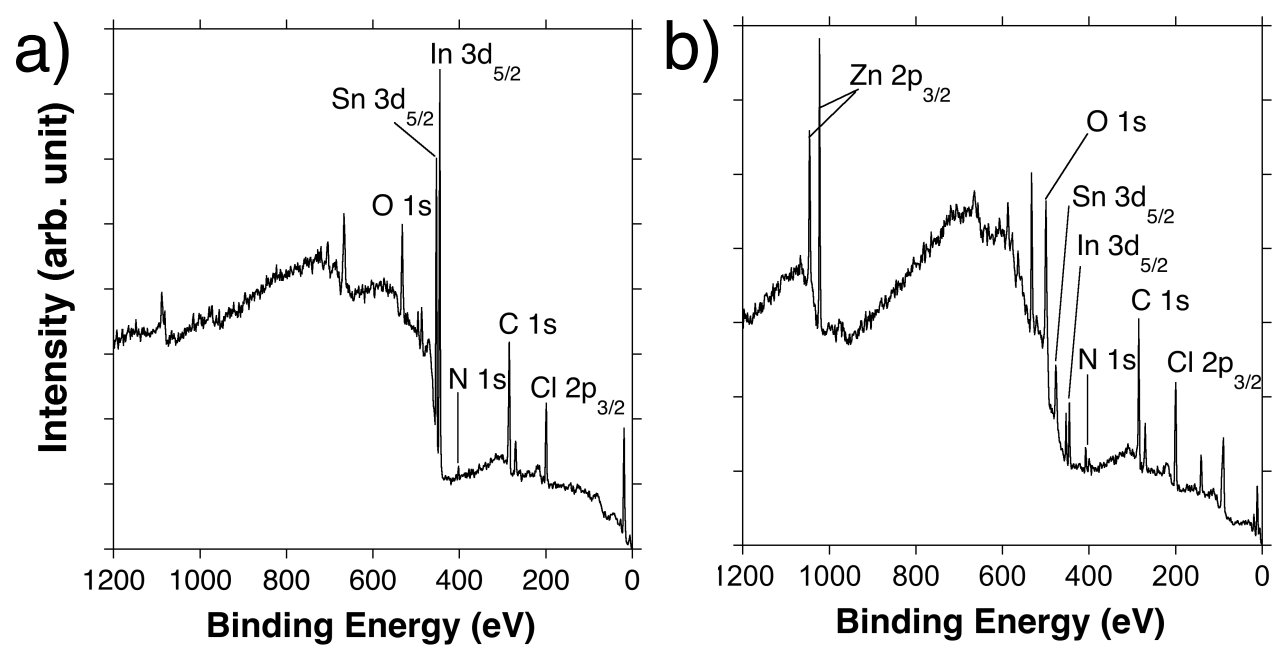

Figure S9. XPS spectra of a) ITO/non-rinsed AAs and b) ITO/ZnO/rinsed AAs.

\section{Fullerene Catching Ability}
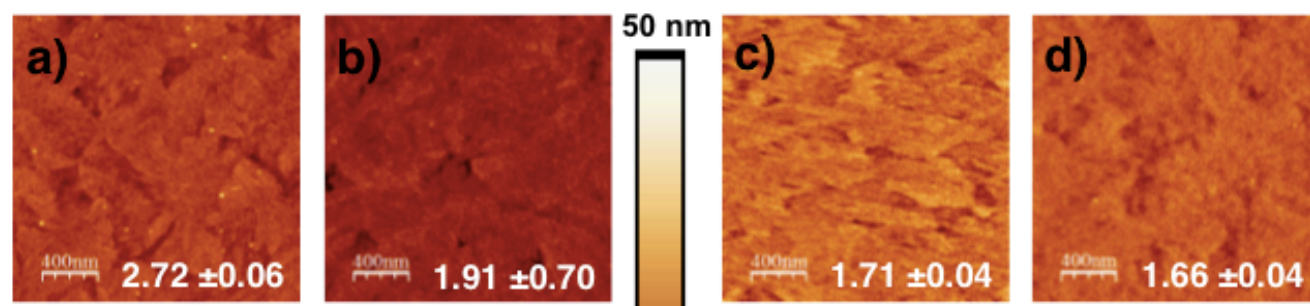

$20 \mathrm{~nm}$
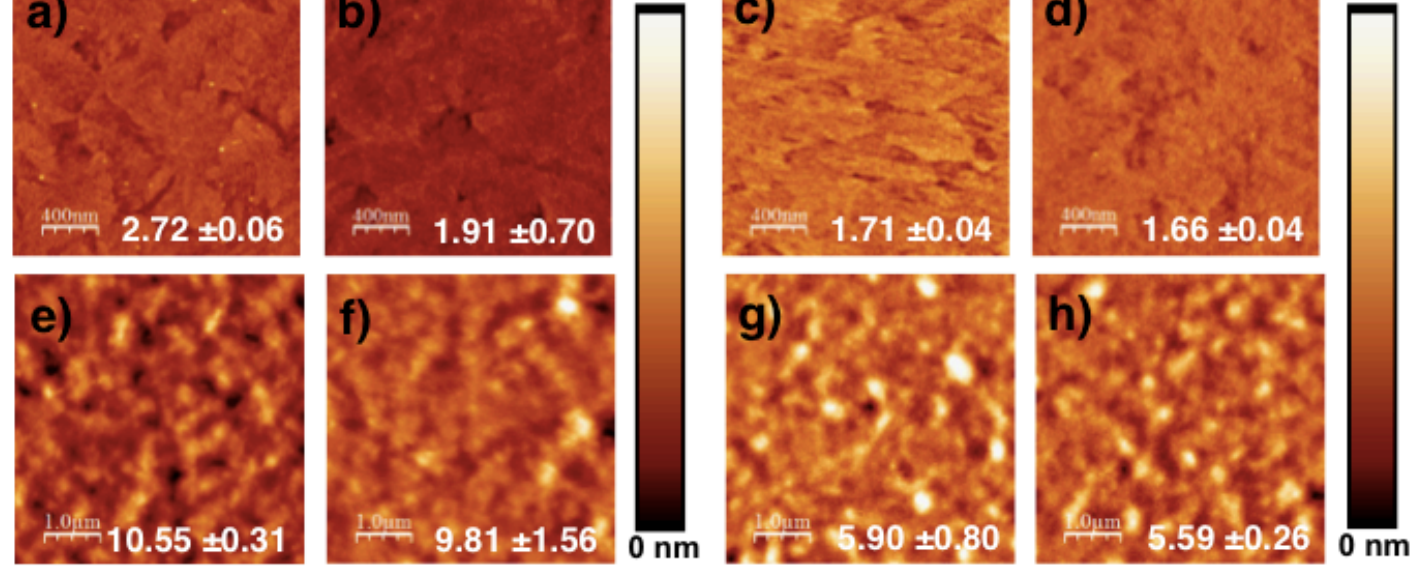

Figure S10. AFM images and r.m.s. roughness values of a) glass/ITO, b) glass/ITO/non-rinsed AAs, c) glass/ITO/ZnO, d) glass/ITO/ZnO/rinsed AAs, e) glass/ITO/P3HT:PCBM, f) glass/ITO/non-rinsed AAs/P3HT:PCBM, g) glass/ITO/ZnO/P3HT:PCBM, and h) glass/ITO/ZnO/rinsed AAs/P3HT:PCBM. 


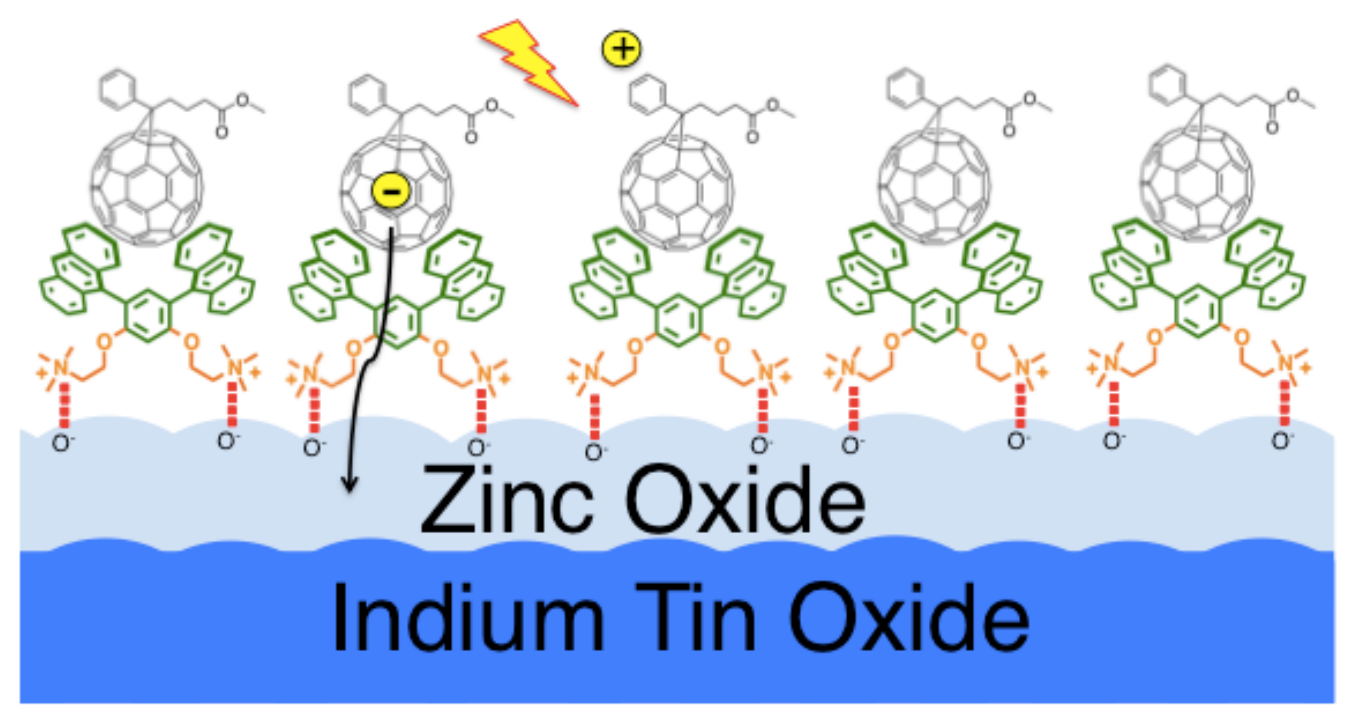

Figure S11. A graphical illustration of the ANTHs interacting with a metal oxide, $\mathrm{ZnO}$ and fullerene derivatives, $\mathrm{PC}_{61} \mathrm{BM}$. 


\section{Device Stability}

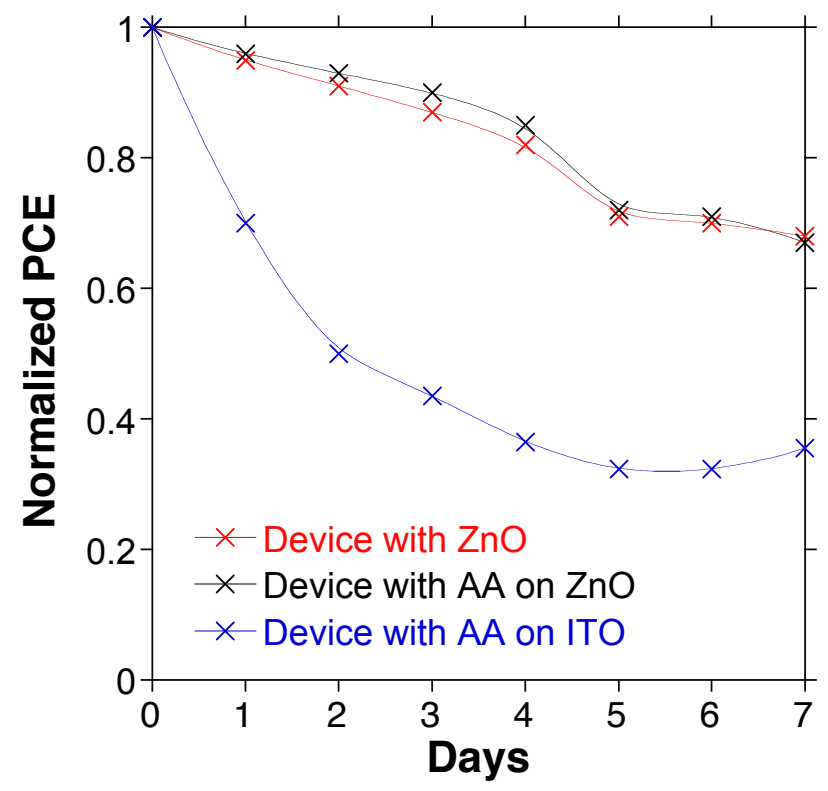

Figure S12. Stability test data of three P3HT:PCBM-based OSCs with $\mathrm{ZnO}$, AA on $\mathrm{ZnO}$, and AA on ITO in ambient conditions (ca. $25^{\circ} \mathrm{C}, 50 \%$ humidity)

\section{Supporting Reference}

(1) Kyaw, A. K.; Wang, D. H.; Gupta, V.; Zhang, J.; Chand, S.; Bazan, G. C.; Heeger, A. J. Efficient Solution-Processed Small-Molecule Solar Cells with Inverted Structure. Adv. Mater. 2013, 25 (17), 2397-2402.

(2) Liao, H.-C.; Lee, C.-H.; Ho, Y.-C.; Jao, M.-H.; Tsai, C.-M.; Chuang, C.-M.; Shyue, J.-J.; Chen, Y.-F.; Su, W.-F. Diketopyrrolopyrrole-Based Oligomer Modified $\mathrm{TiO}_{2}$ Nanorods for Air-Stable and All Solution Processed poly(3hexylthiophene): $\mathrm{TiO}_{2}$ Bulk Heterojunction Inverted Solar Cell. J. Mater. Chem. 2012, 22 (21), 10589-10596.

(3) Riad, A. S.; Mahmoud, S. A.; Ibrahim, A. A. Structural and DC Electrical Investigations of $\mathrm{ZnO}$ Thin Films Prepared by Spray Pyrolysis Technique. Phys. B Condens. Matter 2001, 296 (4), 319-325.

(4) Kondo, K.; Suzuki, A.; Akita, M.; Yoshizawa, M. Micelle-like Molecular Capsules with Anthracene Shells as Photoactive Hosts. Angew. Chemie Int. Ed. 2013, 52 (8), 2308-2312. 